Review Article

\title{
Applications of piggyBac Transposons for Genome Manipulation in Stem Cells
}

\author{
Yi Sun $\mathbb{D}^{1,2}$ Guang Liu $\mathbb{D}^{1,2}$ and Yue Huang $\mathbb{D}^{1,2}$ \\ ${ }^{1}$ State Key Laboratory of Medical Molecular Biology, Institute of Basic Medical Sciences, Chinese Academy of Medical Sciences \& \\ Peking Union Medical College, Beijing 100005, China \\ ${ }^{2}$ Department of Medical Genetics, Institute of Basic Medical Sciences, Chinese Academy of Medical Sciences \& Peking Union \\ Medical College, Beijing 100005, China
}

Correspondence should be addressed to Guang Liu; liuguang@ibms.pumc.edu.cn and Yue Huang; huangyue@pumc.edu.cn

Received 21 May 2021; Accepted 16 August 2021; Published 16 September 2021

Academic Editor: Xinyi Lu

Copyright (C) 2021 Yi Sun et al. This is an open access article distributed under the Creative Commons Attribution License, which permits unrestricted use, distribution, and reproduction in any medium, provided the original work is properly cited.

\begin{abstract}
Transposons are mobile genetic elements in the genome. The piggyBac (PB) transposon system is increasingly being used for stem cell research due to its high transposition efficiency and seamless excision capacity. Over the past few decades, forward genetic screens based on PB transposons have been successfully established to identify genes associated with drug resistance and stem cell-related characteristics. Moreover, PB transposon is regarded as a promising gene therapy vector and has been used in some clinically relevant stem cells. Here, we review the recent progress on the basic biology of $\mathrm{PB}$, highlight its applications in current stem cell research, and discuss its advantages and challenges.
\end{abstract}

\section{Introduction}

In 1981, Evans and Martin isolated and established separately undifferentiated embryonic stem cell (ESC) lines from the inner cell mass (ICM) of mouse blastocysts $[1,2]$. Subsequently, human ESCs (hESCs) were successfully isolated by Thomson et al. [3] in 1998, and hESCs provide unparalleled tools for studying human embryonic development and regenerative medicine [4]. Additionally, mouse-induced pluripotent stem cells (miPSCs) [5] and human iPSCs (hiPSCs) were generated in 2006 and 2007, respectively [6, 7]. Two key features of ESCs and iPSCs are self-renewal, the ability to proliferate indefinitely and pluripotency and the ability to differentiate into various tissue cell types under appropriate culture conditions. As major types of pluripotent stem cells (PSCs), ESCs and iPSCs provide powerful tools to study the gene function. In particular, hiPSCs hold great promise for generating patient-specific human PSCs (hPSCs) for disease modeling and drug discoveries [8]. In addition to PSCs, other types of stem cells derived from postnatal animal tissues are widely used, such as mesenchymal stem cells (MSCs) [9], hematopoietic stem cells (HSCs) [10], and spermatogonial stem cells (SSCs) [11]. Over the past few decades, stem cell biology and mammalian functional genetics studies have developed closely together, yielding remarkable potentials for the application of regenerative medicine to drug discovery, disease modeling, and the development of novel therapeutic strategies [12].

DNA transposons are mobile genetic elements that can move throughout the genome via a "cut-and-paste" mechanism called transposition, and they are usually inactive in rodents and human cells in nature [13]. Over the past two decades, a series of active recombinant transposons have been generated and used as novel tools for functional genomics research in mice and other vertebrates [14]. Among them, Sleeping Beauty (SB) and piggyBac (PB) are the most commonly used eukaryotic DNA transposons $[15,16]$. SB, a Tc1-like transposable element isolated from the salmonid fish genome, was the first transposon used in mouse and human cells $[17,18]$. Although SB can function effectively in mouse somatic cells, it is not highly active in ESCs [19]. $\mathrm{PB}$, however, which is derived from the cabbage looper moth Trichoplusia ni, shows high transposition efficiency in different mammalian cell lines, including ESCs, in addition to 
other organisms [20-22]. Subsequent studies have demonstrated that the translocation activity of $\mathrm{PB}$ is significantly higher than SB in mammalian cell lines [23]. Moreover, unlike SB, which always leaves a $2-5$ bp footprint mutation after mobilization and has a strong tendency for "local hopping (reinsertion close to the original donor site)," $\mathrm{PB}$ exhibits the unique and valuable feature of seamless excision after transposition [24-26]. With the help of the PB system, scores of transgenic animals have been successfully generated, including mice $[20,27]$, rats $[28,29]$, pigs $[30$, 31 ], and goats [32]. Besides, $\mathrm{PB}$ has been used as a nonviral vector for insertional mutagenesis [33], genetic screens [34-38], iPSCs engineering [39-41], gene therapies [15, 42-45], and novel CAR-T cell therapeutic strategies [46-49]. In this review, we will look back to the advancements of $\mathrm{PB}$ transposon in stem cells and regenerative medicine, and discuss its wide applications, so as to provide a reference for future research.

\section{Characteristics of the PB Transposon}

2.1. Integration Site Preference. The PB element was originally discovered in insect cells as a repetitive element while propagating baculovirus in the TN-386 cell line as shown by Fraser et al. [50] and isolated by Cary et al. in 1989 [51]. The inserted mobile DNA was carried by the virus in the form of a "piggyBack," hence the name piggyBac; "Bac" stands for it being a baculovirus-related discovery. In 2005, Ding et al. found that PB elements can actively transpose in a variety of human and mouse cell lines, as well as in mouse germline cells [20]. The original PB element is a $2,475 \mathrm{bp}$ fragment within an open reading frame (ORF) that encodes a functional transposase of 594 amino acids, flanked by 311 bp $5^{\prime}$ end and 235 bp $3^{\prime}$ end sequences, each containing asymmetric inverted terminal repeats (ITRs) carrying transposase binding sites (Figure 1(a)). The $35 \mathrm{bp} 5^{\prime}$ end ITR ( $5^{\prime}$ PBITR) and $63 \mathrm{bp} 3^{\prime}$ end ITR ( $3^{\prime}$ PBITR) were shown to be sufficient for activity both in vivo and in vitro [52]. Importantly, the PB element can be divided into two functional components, ITRs and the PB transposase (PBase), to form a binary transposition system, and have been split into a helper plasmid and a donor plasmid (Figure 1(b)). The PBase, which can be transiently expressed by the helper plasmid, excises any DNA sequence of interest flanked by the ITRs in circular donor plasmid via binding to the ITRs (i.e., cut) and reintegrates the sequence into the TTAA site in the genome (i.e., paste) (Figure 1(c)) [53, 54]. The insertion site can be detected using Splinkerette PCR combined with DNA sequencing $[34,55]$. The further advantage is seamless excision that the reexpression of PBase can remove the transposon completely to obtain transposon-free cells [56].

Several studies have shown that the distribution of PB transposons has no correlation with gene density or expression level, but rather depends on the distribution pattern of TTAA sites [57] and was negatively influenced by genomic methylation [22, 58]. Theoretically, there is an average of one TTAA site every $256 \mathrm{bp}$ (four to the power of four) in the genome, but the protein-coding regions have a higher GC content compared to other positions, leading to a lower frequency of TTAA sites [59]. In addition, only about $1 \%$ of $\mathrm{PB}$ insertion sites are located in the $5^{\prime}$ region within $1000 \mathrm{bp}$ upstream of the transcription start site (TSS), which is much lower than the proportion for retrovirus systems $[22,58,60]$. Compared to lentivirus systems $[21,60]$, PB preferably integrates into genomic safe harbors (GSHs), which are defined based on five criteria for its relative location to ultraconserved regions, noncoding RNAs, and coding genes, especially cancer-related genes $[61,62]$.

2.2. Mutagenic Cassettes. As discussed above, transposons acted as DNA delivery vehicles for genetic modifications. Several PB-based vectors that have been used for insertional mutagenesis contain two main features. These are (1) mutagenic gene trap cassettes to mediate target gene expression (loss or gain-of-function, LOF, or GOF) and (2) reporter cassettes, whose expression is dependent or independent of the correct splicing between exons of the trapped gene and mutagenic gene trap cassettes $[63,64]$. Based on the strategy used for mutating genes, gene trapping can be mainly divided into promoter trapping and polyadenylation (polyA) trapping [65]. In promoter trapping, mutagenic cassettes usually include a splice acceptor (SA) followed by reporter genes and polyA signals in one or both orientations. After integrated into an intron of the expressed gene, the SAreport-polyA element can disrupt the expression of the trapped gene by splicing into upstream exons, which results in a gene trap fusion transcript, and the expression of reporter gene is driven by the endogenous promoter of the trapped gene. As the expression of such a reporter cassette depends on an endogenous promoter, they can only drive transcriptional activation in a tissue of interest [63]. Thus, a reporter driven by an exogenous promoter can be separately used and is independent of the splicing fused transcript, which has allowed more than $90 \%$ of mutational coverage of all mouse genes with unbiased distribution throughout the genome [66]. The reporter cassettes used are usually fluorescent proteins (e.g., green fluorescent protein, GFP; red fluorescent protein, and RFP), antibiotic resistance (puromycin, neomycin, hygromycin, etc.), or $\beta$-galactosidase.

In polyA trapping, transposon insertions utilize a unidirectional exogenous strong promoter followed with a splice donor (SD), but lacks a polyA signal (Figure 1(d)). If the orientation of the exogenous promoter-SD element is consistent with the direction of the transcription of the trapped gene, the element will be spliced into endogenous, downstream exons, hence initiating gene transcription regardless of transcriptional activity [63]. Some trap cassettes with strong viral enhancers/promoters may result in overexpression of truncated or full-length protein products of the trapped gene. Moreover, the promoter of the trapped gene may be transactivated by strong enhancer elements inside the transposon, leading to the overexpression of a fulllength transcript [63]. It is worth noting that vector integrations always tend to occur in the last introns ( $3^{\prime}$-end most) of the trapped gene in poly-A trapping. By inserting an internal ribosome entry site (IRES) sequence between the 
(a)

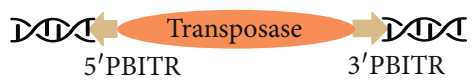

(b)

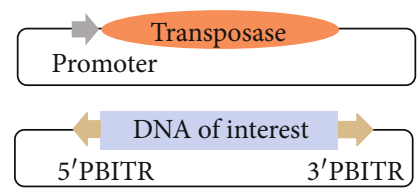

(d)

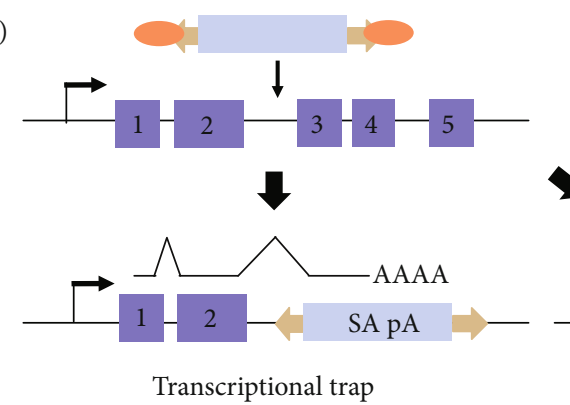

(c)

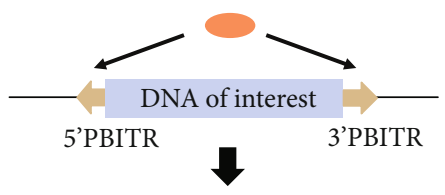

NA of interest

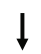

DPC - -

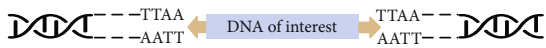

FIgure 1: The piggyBac $(P B)$ transposon System. (a) The original PB elements consist of the transposase gene (orange) and inverted terminal repeats (ITRs, yellow arrows). (b) A binary transposition system for gene delivery in plasmids. One is a transposase expression helper plasmid driven by a promoter (grey arrow), and the other is a donor plasmid that contains a DNA sequence of interest (light purple) and/or drug selection marker flanked by ITRs. (c) Vector-to-chromosome transposition. After cotransfection of the binary system in vitro or in vivo, the transposon carrying a transgene is excised from the donor plasmid and then integrated into the chromosome via transposase interaction with host genome sites containing TTAA segments. (d) Insertion of transposons can disrupt or promote gene expression. In the example shown in this figure, a transposon is integrated between exons 2 and 3 (numbered purple), which may lead to two possible outcomes: (1) the transposon hijacks transcription via the splicing receptor-polyadenylate signaling (SA-ployA) element, disrupting gene function and leading to the trap of transcript expression (exons 1-2), and (2) the transposon drives the expression of downstream gene sequences (exons 3-5) via the promoter-splicing donor (SD) element.

reporter cassette and the SD site to prevent nonsensemediated mRNA decay (NMD) of chimeric transcripts, the bias in the vector integration site can be effectively removed [67]. These features enable the PB system to be a rapid, highthroughput, and traceable mutagenesis tool for constructing mutant libraries for LOF or GOF screening and identification of insertional genes for further validation.

2.3. Cargo Capacity. Genomic sequences contain proteincoding regions and important cis-acting regulatory elements (promoters, enhancers, repressors, etc.) that are essential for appropriate spatial-temporal gene expression. Therefore, the capacity to deliver large cargo is critical for achieving successful gene expression regulation. Retroviral and lentiviral vectors' cargo capacity is restricted to about $10 \mathrm{~kb}$ and also has immunogenic and tumorigenic potential [68]. Nonviral systems, such as SB transposon, are also limited to 5$6 \mathrm{~kb}$ in cargo size and have shown a reduced transposition efficiency when cargo size reaches $10 \mathrm{~kb}$ [69]. These characteristics limit the use of selectable markers, inducible cassettes, and large regulatory sequences. However, Li et al. showed that in mESCs, giant PB transposons could mobilize $100 \mathrm{~kb}$ DNA fragments to endogenous genomic sites with good cargo integrity, and transposons could be seamlessly excised after transposition [70]. Since the transposition efficiency decreases with increasing cargo size, $100 \mathrm{~kb}$ is unlikely to be the upper limit of PB cargo capacity. In general, PB can carry multiple genes during transposition, providing great advantages for multiplexed genetic manipulations, including insertional mutagenesis.

2.4. Transposase. Engineering the PBase is the key to enhancing PB transposition efficiency in mammalian cells. A mouse codon-optimized version of the PBase (mPBase) mediates a 20 -fold increase in vector-to-chromosome transposition relative to the original native version [54] and also elevated the rates of chromosomal transposition from $\mathrm{PB}$ donor loci in mESCs [71]. The enhanced PiggyBac (ePiggyBac) system, which contains a human codon-optimized transposase and the T53C/C136T mutant 5' PBITR, could increase genome integration efficiency by 10 -fold in hESCs [72]. Subsequently, a hyperactive PBase (hyPBase), with a total of 7 amino acids (aa) substitutions as shown by Yusa et al., can mediate more efficient transposition and outperformed the mPBase by 10 -fold without compromising genomic integrity [73]. An in vivo study reported that the hyPBase had a 20-fold increase in the liver-directed expression compared to mPBase [74]. Moreover, it is well known that the PB transposon can be excised by the reexpression of transposase, but there is still the possibility of transposon jumping into new locations. To solve this problem, Li et al. generated an excision competent/integration defective $\left(\mathrm{Exc}^{+} / \mathrm{Int}^{-}\right)$PBase by amino acids mutation at a catalytic domain [75]. As the integration of the PB transposase vector into the host genome may lead to multiple transposition cycles, scientists have discovered that transfection of $\mathrm{PB}$ 
transposase mRNA (a short half-life) instead of a plasmid can effectively reduce the potential genetic toxicity $[76,77]$. An optimized PB transposon system will significantly expand its application in various fields.

2.5. Comparison/Combination with Other Nucleases. The PBase is a very efficient enzyme that actively integrates DNA fragments into the genome in a random manner [78]. Recently, engineered nucleases, including transcription activator-like effector nucleases (TALENs), zinc finger nucleases (ZFNs), and clustered regularly interspaced short palindromic repeats (CRISPR)/CRISPR-associated 9 (Cas9), have been widely used for gene transfer and modification through generating double-strand DNA breaks (DSBs), which can be repaired by homologous directed recombination (HDR) [79]. However, all of these systems exhibit offtarget effects and nonenzymatic DNA insertion [80]. Thus, some works have sought to design PBase fused with these nucleases for integrating DNA into a unique user-defined chromosome site. Although the chimeric TALE-PBase [81] or ZFP-PBase [82] targeting of a unique genomic locus increased transposition efficiency, no targeted transposition was demonstrated [83]. The CRISPR/Cas9 system uses a short guide RNA (sgRNA) to guide the DNA endonuclease Cas 9 to a specific target site and facilitates mutation insertion [84]. A specific Cas9 mutant lacking endonuclease activity (dCas9) fused with transcriptional repressor or activation domains has also been generated to promote transcriptional inhibition or activation when coexpressed with targeted sgRNAs $[85,86]$. Lena et al. fused dCas9 to PBase and targeted it to specific genomic sites using dual sgRNAs [87]. Thus, the ease of design and application of dCas9-PBase, which can edit genes at precise genomic loci, improves future medical applications.

\section{Functional Genomics Using PB-Mediated Genetic Approaches}

Identifying genes that are important for specific biological phenotypes and diseases is a crucial goal of genetic analysis, and genetic screens have proven to be one of the most effective approaches [88]. The reverse genetic analyses are hypothesis-driven investigations of a phenotype driven by the disruption of predefined genes [89], while forward genetic screens are phenotype-derived approaches that generally involve high-throughput mutant libraries generation, specific phenotype selection, and mutations validation [90].

3.1. Loss-of-Function Screening. LOF genetic screens using mammalian cell lines are powerful tools for identifying genes required for many cellular processes. Since ESCs can differentiate into a variety of cell types, including germ cells, and have relatively stable genomes amenable to various genetic manipulations, these cells have become attractive models for analyzing developmental events or disease phenotypes in vitro [80]. With the excellent mutagenic ability of $\mathrm{PB}$ transposon and less bias towards certain genomic hot spots, a genome-wide mutant library could be rapidly and efficiently established in ESCs, allowing researchers to perform phenotype-based genetic screening in mammalian cells, similar to studies that have been done in yeast for the past 30 years [91]. In combination with high-throughput nextgeneration sequencing (NGS) technologies [91, 92], hundreds to thousands of genes trapped by PB transposons could be easily identified, enabling the study of the molecular mechanisms of practically any biological process studied (Table 1).

3.1.1. The Problem of Homozygosity Mutations. Since most of phenotypic changes in mammalian cells require both copies of an autosomal gene to be inactivated (except in some cases of haploinsufficiency) [93], the genome-wide LOF screen of recessive mutations is quite time-consuming and rather difficult using diploid cells [94]. This issue was partially solved by generating a Bloom's syndrome gene(Blm-) deficient ESCs, which lead to a higher rate of mitotic recombination between sister chromatids. Blm-null ESCs harboring heterozygous mutation conversed to homozygous mutations through a loss-of-heterozygosity $(\mathrm{LOH})$, which occurs at a rate of about $10^{-4}$ events/locus/cell/division. Thus, a mutant library needs to be expanded for at least 14 population doublings to promote homozygous mutant generation for further LOF screens, such as the resistance to 6-thioguanine (mismatch repair mutants) and retroviral infection [34, 95-97]. Huang et al. used a PB transposon vector, which carried two drug resistance genes but could express only one at a time and Blm-null ESCs to isolate homozygous mutant cell clones successfully. The two expressed drug-resistant genes could be switched by Cre recombinase, and this allowed selection for the increase in homozygous mutants that occur after LOH [94]. However, due to the low frequency of $\mathrm{LOH}$ in each generation per cell and homozygous cells accounting for only a very small fraction of Blm-null cells, it is not easy to achieve a sufficient number of homozygous mutants for genetic screening [91]. Recently, as an encouraging breakthrough in cell biology, haploid ESC (haESC) lines have been generated in several species, including medaka fish [98], mice [99-102], rats [103], monkeys [104], and humans [105-107]. As there is only one set of chromosomes in haploid cells, it becomes quite easy to generate loss-of-function mutations using haESCs, which hold great promise for both forward and reverse genetic screens [38, 91, 99, 108-116].

3.1.2. Stem Cell Characteristic-Related Screening. Due to the infinite self-renewal ability and haploid properties, haESCs have become powerful tools for generating a tremendous number of homozygous mutation pools [117]. The PB transposon system has also been successfully applied to haESCs to identify different mechanisms of stemness and differentiation. Although the mechanisms of self-renewal of PSCs have become clearer, less is known about how these robust pluripotency programs are modulated to enable fate transitions. PB-mediated large-scale libraries in haESCs for the genetic exploration of the exit-from-pluripotency have been reported, and researchers have identified the RNA binding protein Puml and the conserved small zinc finger protein Zfp706 as being required for exit from self-renewal state timely and efficiently [108]. In addition, the combination 
TABle 1: Genetic screening using PB transposon.

\begin{tabular}{|c|c|c|c|c|c|}
\hline & Screening purpose & Cell type & Strain & Genes identified & Reference \\
\hline \multicolumn{6}{|l|}{ Loss of function } \\
\hline \multirow{11}{*}{ Drug resistance } & 6-thioguanine & $\begin{array}{l}\text { Blm-deficient } \\
\text { ESCs }\end{array}$ & Mouse & Dnmt1 & $\begin{array}{l}\text { Guo et al., } 2004 \\
\quad \text { (ref [96]) }\end{array}$ \\
\hline & 6-thioguanine & haESCs & Mouse & Msh2, Hprt & $\begin{array}{l}\text { Leeb et al., } 2011 \\
\quad(\text { ref }[100])\end{array}$ \\
\hline & 6-thioguanine & haESCs & Mouse & $\begin{array}{l}\text { Mismatch repair genes } \\
(M \operatorname{sh} 2, M \operatorname{sh} 6, M l h 1)\end{array}$ & $\begin{array}{l}\text { Pettitt et al., } 2013 \\
\quad \text { (ref [124]) }\end{array}$ \\
\hline & $\begin{array}{c}\text { Olaparib } \\
\text { (PARP inhibitor) }\end{array}$ & haESCs & Mouse & Parp1 & $\begin{array}{l}\text { Pettitt et al., } 2013 \\
\quad \text { (ref [124]) }\end{array}$ \\
\hline & $\begin{array}{c}\text { Talazoparib } \\
\text { (PARP inhibitor) }\end{array}$ & haESCs & Mouse & Ewsr 1 & $\begin{array}{l}\text { Pettitt et al., } 2017 \\
\quad \text { (ref [113]) }\end{array}$ \\
\hline & Doxorubicin & haESCs & Mouse & $\begin{array}{l}R m i 2 \bowtie P d k 4, \\
\text { and } A c b d 6\end{array}$ & $\begin{array}{l}\text { Liu et al., } 2017 \\
\quad \text { (ref [91]) }\end{array}$ \\
\hline & $\begin{array}{l}\text { Tetrodotoxin-like } \\
\text { toxicant }\end{array}$ & haNPCs & $\begin{array}{l}\text { Rhesus } \\
\text { monkey }\end{array}$ & B4GALT6 & $\begin{array}{l}\text { Wang et al., } 2018 \\
\quad \text { (ref [38]) }\end{array}$ \\
\hline & 6-thioguanine & haTSCs & Mouse & Hprt & $\begin{array}{l}\text { Cui et al., } 2019 \\
\quad \text { (ref [155]) }\end{array}$ \\
\hline & Puromycin & haESCs & Mouse & Lrp6 & $\begin{array}{l}\text { Mao et al., } 2020 \\
\quad(\text { ref }[126])\end{array}$ \\
\hline & Exit from self-renewal & haESCs & Mouse & Zfp706, Pum 1 & $\begin{array}{l}\text { Leeb et al., } 2014 \\
\quad(\text { ref }[108])\end{array}$ \\
\hline & Exit-from-pluripotency & haESCs & Mouse & $\begin{array}{l}\text { Garnl3, Ifltd1, Sema5a, Cdk5rap2 } \\
\text { and Phf21a }\end{array}$ & $\begin{array}{l}\text { Liu et al., } 2017 \\
\quad \text { (ref [91]) }\end{array}$ \\
\hline \multirow[t]{3}{*}{$\begin{array}{l}\text { Stem cell-related } \\
\text { characteristics }\end{array}$} & $\begin{array}{l}\text { Spongiotrophoblast } \\
\text { specification }\end{array}$ & haiTSCs & Mouse & Htral & $\begin{array}{l}\text { Peng et al., } 2019 \\
\quad(\text { ref }[118])\end{array}$ \\
\hline & Reprogramming factors & haEpiSCs & Mouse & $H s 3 s t 3 b 1$ & $\begin{array}{l}\text { Gao et al., } 2021 \\
\quad(\text { ref }[122])\end{array}$ \\
\hline & Haploidy maintenance & haESCs & Mouse & Etl4 & $\begin{array}{l}\text { Zhang et al., } 2020 \\
\text { (ref [123]) }\end{array}$ \\
\hline \multicolumn{6}{|l|}{ Gain of function } \\
\hline \multirow[t]{2}{*}{ Drug resistance } & $\begin{array}{l}\text { PluriSIn-1(SCD1 } \\
\text { inhibitor) }\end{array}$ & ESC & Human & RAS pathway genes & $\begin{array}{l}\text { Weissbein et al., [2019] } \\
\text { (ref [127]) }\end{array}$ \\
\hline & $\begin{array}{l}\text { Ground state } \\
\text { pluripotency }\end{array}$ & EpiSCs & Mouse & $N r 5 a$ & $\begin{array}{l}\text { Guo et al., } 2010 \\
\quad \text { (ref [35]) }\end{array}$ \\
\hline \multirow{3}{*}{$\begin{array}{l}\text { Stem cell-related } \\
\text { characteristics }\end{array}$} & Cell differentiation & ESC & Human & RHOA & $\begin{array}{l}\text { Gayle et al., } 2015 \\
\quad \text { (ref [156]) }\end{array}$ \\
\hline & Growth advantage & ESC & Human & RHO-ROCK pathway genes & $\begin{array}{l}\text { Weissbein et al., } 2019 \\
\text { (ref [127]) }\end{array}$ \\
\hline & Teratoma formation & ESC & Human & $\begin{array}{l}\text { PI3K-AKT and HIPPO pathways } \\
\text { genes }\end{array}$ & $\begin{array}{l}\text { Weissbein et al., } 2019 \\
\text { (ref [127]) }\end{array}$ \\
\hline
\end{tabular}

of PB with newly established haploid stem cell lines from other cell types also plays a vital role in the study of lineage-specific functional genomics. Recently, Cui et al. generated mouse parthenogenetic haploid trophoblast stem cells (haTSCs), which can also serve as a powerful tool for forward genetic screens in placental biology and disorders [117]. In another study, Peng et al. obtained haploidinduced trophoblast stem cells (haiTSCs) from $p 53$-deficient haESCs by overexpressing the $C d x 2$ gene in vitro. $\mathrm{PB}$ mediated high-throughput mutation in haiTSCs was performed and used to screen factors related to the trophoblast lineage, and then Htral was validated as a blocker of spongiotrophoblast specification [118].
Mouse epiblast stem cells (EpiSCs) are derived from the postimplantation egg cylinder epiblast. Unlike ESCs in a naïve pluripotent state, EpiSCs are in a primed pluripotent state and have been widely used to explore the intricate mechanisms of reprogramming [119-121]. Recently, Gao et al. established haploid EpiSCs (haEpiSCs) from mouse postimplantation epiblast at embryonic day 6.5 (E6.5) by microinjecting p53-knockout haESCs into normal blastocysts. Through a massive PB-mediated mutagenesis protocol, researchers determined $H s 3 s t 3 b 1$ as a key modulator that may impede the reprogramming process, providing a valuable resource for reprogramming research [122]. 
Although haploid stem cells have many advantages in genetic screening, the haploid state is generally unstable in culture. As haESCs tend to become diploids spontaneously, it hampers their application in functional genomic researches $[99,100]$. In a recent study, we used a genome-wide haESC homozygous mutant library based on PB transposon mutagenesis to screen the potential haploidy-maintenance factors and found that Etl4-deficiency reduced the rate of selfdiploidization in haESCs. This gene was found to be linked to an energy metabolism transition, thus providing a novel strategy for maintaining haploid status during cell culture by regulating cell metabolism [123].

3.1.3. Drug Resistance Screening. Pettitt et al. used a PB transposon-based dual-directional gene trap vector and mouse haESCs to generate large-scale gene mutant libraries. The resistance to olaparib, a clinical poly (ADP-ribose) polymerase (PARP) inhibitor, was screened, and it was determined that the toxicity of olaparib in normal cells was mainly mediated by PARP1 [124]. At present, almost all reported genetic screens based on mixed mutant pools must rely on strong positive selections of resistant clones, and "negative selection"-based screens are not easy to conduct using these mixed pools due to the possible interference and interplay among different mutant cells, which can interfere with the readout of the quantitative deep sequencing of such a screen [125]. Therefore, we generated arrayed haploid mutant libraries with up to $85 \%$ homozygous mutant clones and then conducted a negative screen to discover mutations conferring sensitivity to the DNA-damaging drug doxorubicin, an anticancer drug frequently used in clinic [91]. Recently, Mao et al. developed an inducible selfinactivating $\mathrm{PB}$ system (named "One-Shot") that allows rapid construction of a mutant library in mouse haESCs and haploid neural stem cell-like cells (haNSCLCs) with single-copy mutation site per cell and puromycin-related resistance was chosen to evaluate this system [126]. Through PB transposons, high-throughput trap mutations can be effectively integrated into haploid neural progenitor cells (haNPCs), which can remain haploid and maintain the potential to differentiate into neurons and glia for long periods in vitro. The target genes of a tetrodotoxin-like toxicant A803467 (B4GALT6) were uncovered subsequently using such a strategy [38]. These studies have expanded the scope of genetic screens in mammalian cells.

3.2. Gain-of-Function Screening. In addition to LOH screens, forward genetic analysis using PB-based GOF mutagenesis enables researchers to more fully explore various biological processes functionally. Since the genetic changes acquired during the culture of hPSCs may influence their availability for research and future treatments, Weissbein et al. used a $\mathrm{PB}$ transposon vector that contained the cytomegalovirus (CMV) enhancer and promoter sequences followed by the SD from the rabbit beta-globin intron, to construct genome-wide libraries of hPSCs. After screening, they uncovered that the overexpression of the RAS pathway led to resistance to the hPSC-specific drug PluriSIn-1, and inac- tivation of the RHO-ROCK pathway resulted in a growth advantage in culture adaptation [127].

As discussed earlier, EpiSCs may be the barrier in somatic cell reprogramming. Therefore, Guo et al. performed a genome-wide $\mathrm{PB}$ insertional activation screen in EpiSCs to identify the factors that can overcome the impediment between EpiSCs and iPSCs [35]. The gene-trap activation vector contained a murine stem cell virus (MSCV) long terminal repeat (LTR) with an SD site from exon 1 of mouse Foxf2, which could promote full or truncated protein expression when integrated upstream or within a gene [128]. To date, GOF screening using transposons has been relatively rare, and this has usually been in combination with a LOF to form a bifunctional activating and inactivating transposon system. For example, transgenic mice with these bifunctional activating and inactivating transposons, which carry different promoter/enhancer elements and bidirectional SA with SV40 polyA signals, have been used for the discovery of oncogenes and tumor suppressor genes [27].

3.3. Comparison with Other Screening Systems. Other forward genetic screening methods in functional genomics research include cDNA libraries, RNA interference (RNAi) libraries, and libraries using the CRISPR/Cas9 system for GOF or LOF screens [129]. Compared with transposoninduced mutagenesis, these methods each have distinct advantages and disadvantages, and the combination of different methods can provide complementary techniques for uncovering functional genes (Table 2).

\section{PB in Stem Cell-Based Preclinical Studies}

Stem cells, as ideal targets for gene therapy, require effective tools for the transient or permanent transfer of genetic information into eukaryotic genomes. Through transposon-based genetic manipulation, therapeutic genes can be introduced with stable phenotypic correction, and stem cells edited can be expanded in vitro, followed by differentiation into particular cell lineages for specific therapeutic needs. Currently, there is widespread evidence that robust transposon-mediated gene transfer can be achieved in several clinically relevant stem cell types, such as hESCs, iPSCs, HSCs, MSCs, or myoblasts.

4.1. hPSCs. Over the past two decades, culture conditions have been a major focus for hPSC research $[3,130]$. Recently, extended or expanded pluripotent stem cells (EPSCs) have been reported to have the additional ability to contribute to both embryonic and extraembryonic tissues [131-133]. It was pointed out that Gao et al. generated doxycycline(Dox-) dependent porcine iPSCs via stable genomic integration of complementary DNA (Yamanaka factors OCT4, MYC, SOX2, and KLF4 together with LIN28, NANOG, $L R H 1$, and $R A R G$ ) in porcine fetal fibroblasts (PFFs) using $\mathrm{PB}$ transposition. Under similar conditions, hESCs and hiPSCs can be transformed into EPSCs $[132,134]$. The successful generation of EPSCs provides tools for embryogenesis and transformation research in regenerative medicine. In addition, hPSCs can also be used for the construction of disease models and therapeutic applications. COVID-19, caused 
TABLE 2: Comparison of genome-wide screening libraries based on cDNA, RNAi, CRISPR/Cas9, and PB transposons.

\begin{tabular}{|c|c|c|c|c|}
\hline & cDNA library & $\begin{array}{l}\text { RNAi } \\
\text { library }\end{array}$ & CRISPR/Cas9 library & piggyBac library \\
\hline Work mode & Gain of function & $\begin{array}{l}\text { Loss of } \\
\text { function }\end{array}$ & Loss of function/gain of function & Loss of function/gain of function \\
\hline Vehicle & cDNA & Sh/siRNA & sgRNA & piggyBac transposon plasmids \\
\hline $\begin{array}{l}\text { Targeting } \\
\text { restrictions }\end{array}$ & Part of transcripts & $\begin{array}{l}\text { Only } \\
\text { targets } \\
\text { mRNA }\end{array}$ & $\begin{array}{l}\text { Protospacer adjacent motif } \\
\text { (PAM) must be present }\end{array}$ & Only at TTAA site \\
\hline $\begin{array}{l}\text { Mutagenesis } \\
\text { efficiency }\end{array}$ & $\begin{array}{l}\quad \geq 2 \text { standard } \\
\text { deviations induced } \\
\text { expression signals }\end{array}$ & $\begin{array}{l}\geq 70 \% \text { gene } \\
\text { knockdown }\end{array}$ & $\begin{array}{l}\text { Knockout, knockdown, or } \\
\text { overexpress with different kinds } \\
\text { of libraries achievable }\end{array}$ & $\begin{array}{l}\text { Activation levels of genes variable, inactivation } \\
\text { achievable in haploidy }\end{array}$ \\
\hline $\begin{array}{l}\text { Genome } \\
\text { coverage }\end{array}$ & $\begin{array}{l}\text { Depend on library } \\
\text { design }\end{array}$ & $\begin{array}{l}\text { Depend on } \\
\text { library } \\
\text { design }\end{array}$ & Depend on library design & $\begin{array}{l}\text { Genome-wide in principle, but influenced by } \\
\text { integration site preference }\end{array}$ \\
\hline $\begin{array}{l}\text { Types of } \\
\text { mutations }\end{array}$ & Overexpression & Knockdown & $\begin{array}{l}\text { Chromosomal deletions and } \\
\text { translocations }\end{array}$ & $\begin{array}{l}\text { Gene activation and inactivation are due to } \\
\text { transposon insertion }\end{array}$ \\
\hline Reversibility & Potentially reversible & $\begin{array}{l}\text { Potentially } \\
\text { reversible }\end{array}$ & $\begin{array}{l}\text { Knockdown or overexpressed } \\
\text { libraries reversible, knockout } \\
\text { libraries irreversible }\end{array}$ & Reversible \\
\hline Limitations & $\begin{array}{l}\text { Abundance of } \\
\text { transcripts varies }\end{array}$ & $\begin{array}{l}\text { High } \\
\text { offtarget } \\
\text { effects }\end{array}$ & Less offtarget effects & $\begin{array}{l}\text { Biallelic gene inactivation rare in diploid cells; } \\
\text { integrations for activation need to be upstream of } \\
\text { the transcription start site }\end{array}$ \\
\hline Cytotoxicity & Variable to high & $\begin{array}{l}\text { Variable to } \\
\text { high }\end{array}$ & Low & Low \\
\hline
\end{tabular}

by severe acute respiratory syndrome coronavirus 2 (SARSCoV-2), has been declared a global pandemic by the World Health Organization. In addition to respiratory failure, COVID-19 can cause clinical complications in other systems, including metabolism, the heart, the nervous system, and the gastrointestinal tract [135]. An hESC line WAe001-A-58 was generated by $\mathrm{PB}$ transposon vector, which carried the Tet-On gene expression system of the SARS-CoV-2 nucleocapsid (N) protein-coding sequence, from the hESC line WA01 (H1), providing an ideal platform for further elucidating the pathological role of the $\mathrm{N}$ protein [136].

4.2. iPSCs. Initially, Dr. Shinya Yamanaka and his colleagues expressed four genes (encoding transcription factors Oct4, Sox2, Klf4, and c-Myc) in somatic cells using retroviruses, and these somatic cells were reprogrammed into an embryonic-like state with similar developmental capabilities [5]. However, due to safety concerns, permanent insertion of the virus in the genome may limit the clinical applications of iPSCs. Using the PB transposon system, mouse and human iPSCs have been successfully generated, and reprogramming factors can be removed from these pluripotent cells without any traces via the reexpression of PBase $[137,138]$, thus minimizing potential concerns associated with insertional oncogenesis. To better control copy numbers in the genome, all four reprogramming factors can be introduced into one vector using approximately 20 amino acid long self-cleaving $2 \mathrm{~A}$ peptides to separate these different genes [137, 138].

In recent years, $\mathrm{PB}$ transposons, combined with TALENs or the CRISPR/Cas9 system, have been used for the genome editing of iPSCs to correct gene defects $[25,26,139,140]$. Genome editing relies on the introduction of double-strand breaks at target sites using "nucleases" to allow the occurrences of error-prone nonhomologous end-joining (NHEJ) or HDR near the nuclease cutting site, followed by the traceless removal of selectable gene fragments via PBase [24]. This strategy has recently been used to achieve the correction of mutations in the hemoglobin beta chain gene. By combining PB with TALENs or CRISPR/Cas9, the mutated $\beta$-globin gene in sickle cell disease- (SCD-) specific iPSCs or $\beta$-thalassemia patient-derived iPSCs was successfully seamlessly corrected without any detectible offtarget or adverse chromosomal alterations [25, 26]. Similarly, it has recently been shown in iPSCs derived from patients with Huntington's disease that the combination of $\mathrm{PB}$ transposon with the CRISPR/Cas9 system may support gene therapy in these genetic disorders induced by trinucleotide repeat expansion [141]. Corrected stem cells successfully differentiated into excitable, synaptically active forebrain neurons.

Genetic manipulation of iPSCs before transplantation may further threaten genomic stability, which can affect their differentiation, characterization, tumorigenicity, and uncontrolled cellular behavior [142]. Therefore, wholegenome sequencing is needed to detect such changes [143], and more preclinical trials in mice and other animal models will be necessary to further confirm the therapeutic potential of reprogrammed cells in vivo [144].

4.3. HSCs. HSCs are ideal tools for gene therapy in hematologic diseases due to their ability for self-renew and differentiation into different lymphohematopoietic lineages. The PB 
transposon system has been used for stable gene transfer of CD34+ HSCs; although, comparative analysis has shown higher activity of SB100X, the most hyperactive version of the SB transposase currently $[145,146]$. PB transposonmodified HSCs continue to express functional globin chain proteins, exhibiting a reduced sickle phenotype and an improvement in disease progression. Later, the hyPBase, which is more active than SB100X in other cell types, has been developed [147], but the comparison with SB100X in HSCs has not been performed yet.

4.4. Mesenchymal/Stromal Stem Cells. Human MSCs originate from human embryonic mesoderm and/or can be isolated from fetal and adult tissues, such as bone marrow (BM), umbilical cord (UC), adipose, etc. [9], and are a heterogeneous subset of nonhematopoietic multipotent stromal stem cells. MSCs can be differentiated into ectodermal (e.g., neuronal cells), mesodermal (e.g., osteocytes, chondrocytes and adipocytes), and endodermal lineages (e.g., hepatocytes). It has been reported that the PB system was applicable to gene integration in MSCs [148]. Yang et al. generated immortalized human UC-derived MSCs (iUCMSCs) using the PB-based monkey virus $40 \mathrm{~T}$ antigen (SV40T) system. These cells positively expressed MSC markers and did not induce tumorigenesis in vivo with the retained potential for trilineage differentiation after BMP9 stimulation, which has laid a foundation for further study and applications in UC-MSCs [149]. Moreover, MSCs are considered excellent cancer therapeutic tools in view of their unique ability to target tumor cells. Interferon-gamma(IFN- $\gamma_{-}$) expressing adipose-derived MSCs (AD-MSCs) generated by $\mathrm{PB}$-mediated gene transfer were engrafted into tumor stroma in a mouse model of melanoma and could inhibit tumor growth and angiogenesis, prolong the survival of mice and exhibit an important implication for future cancer treatment [150].

4.5. Myoblasts. Myoblasts are self-renewing adult muscle progenitor cells that can eventually differentiate into skeletal muscle fibers for the potential treatment of muscle disorders. Reports have shown that PB-mediated gene transfer can be used to deliver therapeutic genes into myoblasts effectively. Based on the use of the PB transposon system, the genes encoding either full-length human dystrophin or truncated microdystrophins could be successfully introduced into myoblasts and expressed in differentiated multinucleated myotubules [151], paving the way toward a PB-mediated gene therapy approach for Duchenne muscular dystrophy (DMD).

4.6. Safety Issues of piggyBac. DNA transposons allow nonviral stable gene transfer and potentially replace the need for viral vectors, but there are still a few safety issues to consider carefully.

(i) Insertional mutagenesis is one of the major concerns of any integration-based gene therapy. Since $\mathrm{PB}$ transposons exhibit a higher integration preference for transcriptional units, they may potentially lead to the activation of oncogenes or the disruption of tumor suppressor genes, thus promoting malignant transformation. It has been reported that no growth advantage was observed in PB-modified primary human cells during a 140-day experiment [152], and no observable tumor formation was found in livers of wild-type mice modified with $\mathrm{PB}$ for one year [153]. In addition, transposon integrations can be redirected to a demonstrated safeharbor site, which can be achieved by transposase modified to carry site-specific DNA binding domains at its $\mathrm{N}$ - or C-termini [82]

(ii) Investigators have found that the probability of plasmid backbone DNA integration is relatively high in PB-modified human embryonic kidney (HEK-293) cells [152]. Although this problem can be nearly eliminated by flow cytometry to sort cells based on characteristic elements in the integrated backbone, it still requires close attention. Besides, it remains to be further explored if plasmid backbone integration exists in clinically relevant cells and animal models

(iii) Previous studies [51] have reported that the $5^{\prime}$ PBITR has potential promoter activity. To avoid possible influence, gene-trap cassettes could be placed opposite the $5^{\prime}$ PBITR for chromatin integration [52]

(iv) Despite the widespread assumption that nonviral vectors should not elicit any immune response, foreign DNA itself has the potential to activate the innate immune system [154]. Thus, some immune regulation may still be needed after stable transposition into the host genome

\section{Conclusions and Perspectives}

Transposon-based technologies hold great promise for the development of powerful genomic tools. There is no doubt that there will be more reports in the future using $\mathrm{PB}$ for gene delivery in stem cells and other fields of research. By combining transposon technology with accurate gene editing techniques, the continued development, refinement, and clinical transformation using PB may herald an exciting and promising new era of gene therapy.

\section{Data Availability}

No data is available.

\section{Conflicts of Interest}

The authors declare that they have no conflict of interest.

\section{Authors' Contributions}

Y. H. conceived and designed the study. Y. S. and G. L. were engaged in data collection, organization, and analyses. The manuscript was written and revised by Y. S., G. L., and Y. H. 


\section{Acknowledgments}

We are grateful to Meili Zhang for helpful discussion and comments on the manuscript. This work was supported by the National Key Research and Development Program of China (2016YFA0100103 to Y.H.), CAMS Innovation Fund for Medical Sciences (2016-I2M-3-002 to Y.H. and G.L.), and National Natural Science Foundation of China (31970813 to Y.H.).

\section{References}

[1] M. J. Evans and M. H. Kaufman, "Establishment in culture of pluripotential cells from mouse embryos," Nature, vol. 292, no. 5819 , pp. $154-156,1981$.

[2] G. R. Martin, "Isolation of a pluripotent cell line from early mouse embryos cultured in medium conditioned by teratocarcinoma stem cells," Proceedings of the National Academy of Sciences of the United States of America, vol. 78, no. 12, pp. 7634-7638, 1981.

[3] J. A. Thomson, J. Itskovitz-Eldor, S. S. Shapiro et al., "Embryonic stem cell lines derived from human blastocysts," Science, vol. 282, no. 5391, pp. 1145-1147, 1998.

[4] B. E. Reubinoff, M. F. Pera, C. Y. Fong, A. Trounson, and A. Bongso, "Embryonic stem cell lines from human blastocysts: somatic differentiation in vitro," Nature Biotechnology, vol. 18, no. 4, pp. 399-404, 2000.

[5] K. Takahashi and S. Yamanaka, "Induction of pluripotent stem cells from mouse embryonic and adult fibroblast cultures by defined factors," Cell, vol. 126, no. 4, pp. 663-676, 2006.

[6] J. Yu, M. A. Vodyanik, K. Smuga-Otto et al., "Induced pluripotent stem cell lines derived from human somatic cells," Science, vol. 318, no. 5858, pp. 1917-1920, 2007.

[7] K. Takahashi, K. Tanabe, M. Ohnuki et al., "Induction of pluripotent stem cells from adult human fibroblasts by defined factors," Cell, vol. 131, no. 5, pp. 861-872, 2007.

[8] R. G. Rowe and G. Q. Daley, "Induced pluripotent stem cells in disease modelling and drug discovery," Nature Reviews Genetics, vol. 20, no. 7, pp. 377-388, 2019.

[9] P. Bianco, “"Mesenchymal” stem cells,” Annual Review of Cell and Developmental Biology, vol. 30, no. 1, pp. 677-704, 2014.

[10] E. Dzierzak and A. Bigas, "Blood development: hematopoietic stem cell dependence and independence," Cell Stem Cell, vol. 22, no. 5, pp. 639-651, 2018.

[11] A. de Los Angeles, F. Ferrari, R. Xi et al., "Hallmarks of pluripotency," Nature, vol. 525, no. 7570, pp. 469-478, 2015.

[12] D. Cyranoski, "How human embryonic stem cells sparked a revolution," Nature, vol. 555, no. 7697, pp. 428-430, 2018.

[13] R. K. Aziz, M. Breitbart, and R. A. Edwards, "Transposases are the most abundant, most ubiquitous genes in nature," Nucleic Acids Research, vol. 38, no. 13, pp. 4207-4217, 2010.

[14] G. Bourque, K. H. Burns, M. Gehring et al., "Ten things you should know about transposable elements," Genome Biology, vol. 19, no. 1, p. 199, 2018.

[15] J. Tipanee, Y. C. Chai, T. VandenDriessche, and M. K. Chuah, "Preclinical and clinical advances in transposon-based gene therapy," Bioscience Reports, vol. 37, article BSR20160614, 2017.

[16] J. Tipanee, T. VandenDriessche, and M. K. Chuah, "Transposons: moving forward from preclinical studies to clinical tri- als," Human Gene Therapy, vol. 28, no. 11, pp. 1087-1104, 2017.

[17] Z. Ivics, P. B. Hackett, R. H. Plasterk, and Z. Izsvak, "Molecular Reconstruction of Sleeping Beauty, a Tc1-like Transposon from Fish, and Its Transposition in Human Cells," Cell, vol. 91, no. 4, pp. 501-510, 1997.

[18] L. S. Collier, C. M. Carlson, S. Ravimohan, A. J. Dupuy, and D. A. Largaespada, "Cancer gene discovery in solid tumours using transposon-based somatic mutagenesis in the mouse," Nature, vol. 436, no. 7048, pp. 272-276, 2005.

[19] G. Luo, Z. Ivics, Z. Izsvak, and A. Bradley, "Chromosomal transposition of a Tc1/mariner-like element in mouse embryonic stem cells," Proceedings of the National Academy of Sciences of the United States of America, vol. 95, no. 18, pp. 10769-10773, 1998.

[20] S. Ding, X. Wu, G. Li, M. Han, Y. Zhuang, and T. Xu, "Efficient Transposition of the piggyBac (PB) Transposon in Mammalian Cells and Mice," Cell, vol. 122, no. 3, pp. 473483, 2005.

[21] M. H. Wilson, C. J. Coates, and A. L. George Jr., "PiggyBac Transposon-mediated Gene Transfer in Human Cells," Molecular Therapy, vol. 15, no. 1, pp. 139-145, 2007.

[22] W. Wang, C. Lin, D. Lu et al., "Chromosomal transposition of PiggyBac in mouse embryonic stem cells," Proceedings of the National Academy of Sciences of the United States of America, vol. 105, no. 27, pp. 9290-9295, 2008.

[23] S. C. Wu, Y. J. Meir, C. J. Coates et al., "piggyBac is a flexible and highly active transposon as compared to sleeping beauty, Tol2, and Mos1 in mammalian cells," Proceedings of the National Academy of Sciences of the United States of America, vol. 103, no. 41, pp. 15008-15013, 2006.

[24] Q. Chen, W. Luo, R. A. Veach, A. B. Hickman, M. H. Wilson, and F. Dyda, "Structural basis of seamless excision and specific targeting by _piggyBac_transposase," Nature Communications, vol. 11, no. 1, p. 3446, 2020.

[25] N. Sun and H. Zhao, "Seamless correction of the sickle cell disease mutation of the HBB gene in human induced pluripotent stem cells using TALENs," Biotechnology and Bioengineering, vol. 111, no. 5, pp. 1048-1053, 2014.

[26] F. Xie, L. Ye, J. C. Chang et al., "Seamless gene correction of $\beta$-thalassemia mutations in patient-specific iPSCs using CRISPR/Cas9 andpiggyBac," Genome Research, vol. 24, no. 9, pp. 1526-1533, 2014.

[27] R. Rad, L. Rad, W. Wang et al., "PiggyBac transposon mutagenesis: a tool for cancer gene discovery in mice," Science, vol. 330, no. 6007, pp. 1104-1107, 2010.

[28] T. Li, L. Shuai, J. Mao et al., "Efficient Production of Fluorescent Transgenic Rats using the piggyBac Transposon," Scientific Reports, vol. 6, no. 1, article 33225, 2016.

[29] M. G. Jiang, T. Li, C. Feng et al., "Generation of Transgenic Rats through Induced Pluripotent Stem Cells," The Journal of Biological Chemistry, vol. 288, no. 38, pp. 27150-27158, 2013.

[30] Z. Wu, Z. Xu, X. Zou et al., "Pig transgenesis by piggyBac transposition in combination with somatic cell nuclear transfer," Transgenic Research, vol. 22, no. 6, pp. 11071118, 2013.

[31] Z. Li, F. Zeng, F. Meng et al., "Generation of transgenic pigs by cytoplasmic injection of piggyBac transposase-based pmGENIE-3 plasmids," Biology of Reproduction, vol. 90, no. 5 , p. $93,2014$. 
[32] D. P. Bai, M. M. Yang, L. Qu, and Y. L. Chen, "Generation of a transgenic cashmere goat using the piggyBac transposition system," Theriogenology, vol. 93, pp. 1-6, 2017.

[33] M. J. Friedrich, I. F. Bronner, P. Liu, A. Bradley, and R. Rad, "PiggyBac Transposon-Based Insertional Mutagenesis in Mice," in Cancer Driver Genes, pp. 171-183, 2019.

[34] W. Wang, A. Bradley, and Y. Huang, "A piggyBac transposon-based genome-wide library of insertionally mutated Blm-deficient murine ES cells," Genome Research, vol. 19, no. 4, pp. 667-673, 2009.

[35] G. Guo and A. Smith, "A genome-wide screen in EpiSCs identifies Nr5a nuclear receptors as potent inducers of ground state pluripotency," Development, vol. 137, no. 19, pp. 3185-3192, 2010.

[36] J. Bai, K. Li, W. Tang et al., "A high-throughput screen for genes essential for PRRSV infection using a piggyBac based system," Virology, vol. 531, pp. 19-30, 2019.

[37] J. Weber, J. de la Rosa, C. S. Grove et al., “_PiggyBac_transposon tools for recessive screening identify B-cell lymphoma drivers in mice," Nature Communications, vol. 10, no. 1, p. 1415, 2019.

[38] H. Wang, W. Zhang, J. Yu et al., "Genetic screening and multipotency in rhesus monkey haploid neural progenitor cells," Development, vol. 145, article dev160531, 2018.

[39] J. M. Vanslambrouck, L. E. Woodard, N. Suhaimi et al., "Direct reprogramming to human nephron progenitor-like cells using inducible _piggyBac_ transposon expression of _SNAI2-EYA1-SIX1_," Kidney International, vol. 95, no. 5, pp. 1153-1166, 2019.

[40] M. A. Park, H. S. Jung, and I. Slukvin, "Genetic engineering of human pluripotent stem cells using PiggyBac transposon system," Current Protocols in Stem Cell Biology, vol. 47, no. 1, p. e63, 2018.

[41] M. G. Garone, V. de Turris, A. Soloperto et al., "Conversion of human induced pluripotent stem cells (iPSCs) into functional spinal and cranial motor neurons using PiggyBac vectors," Journal of Visualized Experiments, vol. 2019, no. 147, 2019.

[42] L. E. Woodard and M. H. Wilson, "piggyBac-ing models and new therapeutic strategies," Trends in Biotechnology, vol. 33, no. 9, pp. 525-533, 2015.

[43] M. Cheng, X. Jin, L. Mu et al., "Combination of the clustered regularly interspaced short palindromic repeats (CRISPR)associated 9 technique with the piggybac transposon system for mouse in utero electroporation to study cortical development," Journal of Neuroscience Research, vol. 94, no. 9, pp. 814-824, 2016.

[44] B. E. Hew, R. Sato, D. Mauro, I. Stoytchev, and J. B. Owens, "RNA-guided piggyBac transposition in human cells," Synthetic Biology, vol. 4, no. 1, article ysz018, 2019.

[45] S. Liu, Q. Wang, X. Yu et al., "HIV-1 inhibition in cells with CXCR4 mutant genome created by CRISPR-Cas9 and _piggyBac_recombinant technologies," Scientific Reports, vol. 8, no. 1, p. 8573, 2018.

[46] D. Morita, N. Nishio, S. Saito et al., "Enhanced Expression of Anti-CD19 Chimeric Antigen Receptor in _piggyBac Transposon-Engineered T Cells," Molecular TherapyMethods \& Clinical Development, vol. 8, pp. 131-140, 2018.

[47] P. Ptackova, J. Musil, M. Stach et al., "A new approach to $\mathrm{CAR} \mathrm{T}$-cell gene engineering and cultivation using piggyBac transposon in the presence of IL-4, IL-7 and IL-21," Cytother$a p y$, vol. 20, no. 4, pp. 507-520, 2018.

[48] Z. Zhang, D. Jiang, H. Yang et al., "Modified CAR T cells targeting membrane-proximal epitope of mesothelin enhances the antitumor function against large solid tumor," Cell Death \& Disease, vol. 10, no. 7, p. 476, 2019.

[49] D. C. Bishop, L. E. Clancy, R. Simms et al., "Development of CAR T-cell lymphoma in two of ten patients effectively treated with piggyBac modified CD19 CAR T-cells," Blood, no. article 2021010813, 2021.

[50] M. J. Fraser, G. E. Smith, and M. D. Summers, "Acquisition of Host Cell DNA sequences by baculoviruses: relationship between host DNA insertions and FP mutants of Autographa californica and galleria mellonella nuclear polyhedrosis viruses," Journal of Virology, vol. 47, no. 2, pp. 287-300, 1983.

[51] L. C. Cary, M. Goebel, B. G. Corsaro, H.-G. Wang, E. Rosen, and M. J. Fraser, "Transposon mutagenesis of baculoviruses: Analysis of Trichoplusia ni transposon IFP2 insertions within the FP-locus of nuclear polyhedrosis viruses," Virology, vol. 172, no. 1, pp. 156-169, 1989.

[52] V. Solodushko, V. Bitko, and B. Fouty, "Minimal piggyBac vectors for chromatin integration," Gene Therapy, vol. 21, no. 1, pp. 1-9, 2014.

[53] Z. Ivics, M. A. Li, L. Mates et al., "Transposon-mediated genome manipulation in vertebrates," Nature Methods, vol. 6, no. 6, pp. 415-422, 2009.

[54] J. Cadinanos and A. Bradley, "Generation of an inducible and optimized piggyBac transposon system," Nucleic Acids Research, vol. 35, no. 12, p. e87, 2007.

[55] H. Mikkers, J. Allen, P. Knipscheer et al., "High-throughput retroviral tagging to identify components of specific signaling pathways in cancer," Nature Genetics, vol. 32, no. 1, pp. 153159, 2002.

[56] M. J. Fraser, L. Cary, K. Boonvisudhi, and H. G. Wang, "Assay for movement of Lepidopteran transposon IFP2 in insect cells using a baculovirus genome as a target DNA," Virology, vol. 211, no. 2, pp. 397-407, 1995.

[57] B. Troyanovsky, V. Bitko, V. Pastukh, B. Fouty, and V. Solodushko, "The functionality of minimal PiggyBac transposons in mammalian cells," Molecular Therapy Nucleic Acids, vol. 5, p. e369, 2016.

[58] D. Yang, R. Liao, Y. Zheng, L. Sun, and T. Xu, "Analysis of PBase binding profile indicates an insertion target selection mechanism dependent on TTAA, but not transcriptional activity," International Journal of Biological Sciences, vol. 12, no. 9, pp. 1074-1082, 2016.

[59] K. Yusa, "Seamless genome editing in human pluripotent stem cells using custom endonuclease-based gene targeting and the piggyBac transposon," Nature Protocols, vol. 8, no. 10, pp. 2061-2078, 2013.

[60] M. Hamada, N. Nishio, Y. Okuno et al., "Integration Mapping of piggyBac-Mediated CD19 Chimeric Antigen Receptor $\mathrm{T}$ Cells Analyzed by Novel Tagmentation-Assisted PCR," eBioMedicine, vol. 34, pp. 18-26, 2018.

[61] E. P. Papapetrou, G. Lee, N. Malani et al., "Genomic safe harbors permit high $\beta$-globin transgene expression in thalassemia induced pluripotent stem cells," Nature Biotechnology, vol. 29, no. 1, pp. 73-78, 2011.

[62] E. P. Papapetrou and A. Schambach, "Gene insertion into genomic safe harbors for human gene therapy," Molecular Therapy, vol. 24, no. 4, pp. 678-684, 2016. 
[63] K. Kawakami, D. A. Largaespada, and Z. Ivics, "Transposons as tools for functional genomics in vertebrate models," Trends in Genetics, vol. 33, no. 11, pp. 784-801, 2017.

[64] W. L. Stanford, J. B. Cohn, and S. P. Cordes, "Gene-trap mutagenesis: past, present and beyond," Nature Reviews. Genetics, vol. 2, no. 10, pp. 756-768, 2001.

[65] R. H. Friedel and P. Soriano, "Gene trap mutagenesis in the mouse," Methods in Enzymology, vol. 477, pp. 243-269, 2010.

[66] A. Gragerov, K. Horie, M. Pavlova et al., "Large-scale, saturating insertional mutagenesis of the mouse genome," Proceedings of the National Academy of Sciences of the United States of America, vol. 104, no. 36, pp. 1440614411, 2007.

[67] T. Shigeoka, M. Kawaichi, and Y. Ishida, "Suppression of nonsense-mediated mRNA decay permits unbiased gene trapping in mouse embryonic stem cells," Nucleic Acids Research, vol. 33, no. 2, p. e20, 2005.

[68] M. Di Matteo, E. Belay, M. K. Chuah, and T. Vandendriessche, "Recent developments in transposonmediated gene therapy," Expert Opinion on Biological Ther$a p y$, vol. 12, no. 7, pp. 841-858, 2012.

[69] H. Zayed, Z. Izsvak, O. Walisko, and Z. Ivics, "Development of Hyperactive Sleeping Beauty Transposon Vectors by Mutational Analysis," Molecular Therapy, vol. 9, no. 2, pp. 292-304, 2004.

[70] M. A. Li, D. J. Turner, Z. Ning et al., "Mobilization of giant piggyBac transposons in the mouse genome," Nucleic Acids Research, vol. 39, no. 22, p. e148, 2011.

[71] Q. Liang, J. Kong, J. Stalker, and A. Bradley, "Chromosomal mobilization and reintegration of sleeping beauty and PiggyBac transposons," Genesis, vol. 47, no. 6, pp. 404-408, 2009.

[72] A. Lacoste, F. Berenshteyn, and A. H. Brivanlou, "An efficient and reversible transposable system for gene delivery and lineage- specific differentiation in human embryonic stem cells," Cell Stem Cell, vol. 5, no. 3, pp. 332-342, 2009.

[73] K. Yusa, L. Zhou, M. A. Li, A. Bradley, and N. L. Craig, “A hyperactive piggyBac transposase for mammalian applications," Proceedings of the National Academy of Sciences of the United States of America, vol. 108, no. 4, pp. 1531-1536, 2011.

[74] M. di Matteo, E. Samara-Kuko, N. J. Ward et al., "Hyperactive PiggyBac Transposons for Sustained and Robust Livertargeted Gene Therapy," Molecular Therapy, vol. 22, no. 9, pp. 1614-1624, 2014.

[75] X. Li, E. R. Burnight, A. L. Cooney et al., "piggyBac transposase tools for genome engineering," Proceedings of the National Academy of Sciences of the United States of America, vol. 110, no. 25, pp. E2279-E2287, 2013.

[76] S. Bire, D. Ley, S. Casteret, N. Mermod, Y. Bigot, and F. Rouleux-Bonnin, "Optimization of the piggyBac transposon using mRNA and insulators: toward a more reliable gene delivery system," PLoS One, vol. 8, no. 12, article e82559, 2013.

[77] S. Bire, N. Ishac, and F. Rouleux-Bonnin, "In vitro synthesis, delivery, and bioavailability of exogenous mRNA in gene transfer mediated by PiggyBac transposition," Methods in Molecular Biology, vol. 1428, pp. 187-217, 2016.

[78] R. Mitra, J. Fain-Thornton, and N. L. Craig, "piggyBac can bypass DNA synthesis during cut and paste transposition," The EMBO Journal, vol. 27, no. 7, pp. 1097-1109, 2008.
[79] T. Gaj, C. A. Gersbach, and C. F. Barbas 3rd., "ZFN, TALEN, and CRISPR/Cas-based methods for genome engineering," Trends in Biotechnology, vol. 31, no. 7, pp. 397-405, 2013.

[80] W. T. Hendriks, C. R. Warren, and C. A. Cowan, "Genome editing in human pluripotent stem cells: approaches, pitfalls, and solutions," Cell Stem Cell, vol. 18, no. 1, pp. 53-65, 2016.

[81] J. B. Owens, D. Mauro, I. Stoytchev et al., "Transcription activator like effector (TALE)-directed piggyBac transposition in human cells," Nucleic Acids Research, vol. 41, no. 19, pp. 9197-9207, 2013.

[82] C. Kettlun, D. L. Galvan, A. L. George Jr., A. Kaja, and M. H. Wilson, "Manipulating piggyBac Transposon Chromosomal Integration Site Selection in Human Cells," Molecular Therapy, vol. 19, no. 9, pp. 1636-1644, 2011.

[83] L. Ye, Z. You, Q. Qian et al., "TAL effectors mediate highefficiency transposition of the piggyBac transposon in silkworm Bombyx mori L," Scientific Reports, vol. 5, no. 1, article 17172, 2015.

[84] L. Cong, F. A. Ran, D. Cox et al., "Multiplex genome engineering using CRISPR/Cas systems," Science, vol. 339, no. 6121, pp. 819-823, 2013.

[85] L. A. Gilbert, M. H. Larson, L. Morsut et al., "CRISPR-mediated modular RNA-guided regulation of transcription in eukaryotes," Cell, vol. 154, no. 2, pp. 442-451, 2013.

[86] S. Konermann, M. D. Brigham, A. E. Trevino et al., "Genome-scale transcriptional activation by an engineered CRISPR-Cas9 complex," Nature, vol. 517, no. 7536, pp. 583-588, 2015.

[87] L. Goshayeshi, S. Yousefi Taemeh, N. Dehdilani, M. Nasiri, M. M. Ghahramani Seno, and H. Dehghani, "CRISPR/dCas9-mediated transposition with specificity and efficiency of site-directed genomic insertions," The FASEB Journal, vol. 35, no. 2, article e21359, 2021.

[88] M. A. Li, S. J. Pettitt, K. Yusa, and A. Bradley, "Genome-wide forward genetic screens in mouse ES cells," Methods in Enzymology, vol. 477, pp. 217-242, 2010.

[89] S. Hardy, V. Legagneux, Y. Audic, and L. Paillard, "Reverse genetics in eukaryotes," Biology of the Cell, vol. 102, no. 10, pp. 561-580, 2010.

[90] E. M. Moresco, X. Li, and B. Beutler, "Going forward with genetics: recent technological advances and forward genetics in mice," The American Journal of Pathology, vol. 182, no. 5, pp. 1462-1473, 2013.

[91] G. Liu, X. Wang, Y. Liu et al., "Arrayed mutant haploid embryonic stem cell libraries facilitate phenotype-driven genetic screens," Nucleic Acids Research, vol. 45, no. 22, p. e180, 2017.

[92] C. Mayor-Ruiz, O. Dominguez, and O. Fernandez-Capetillo, "Trap ${ }^{\text {Seq. }}$ An RNA Sequencing-Based Pipeline for the Identification of Gene-Trap Insertions in Mammalian Cells," Journal of Molecular Biology, vol. 429, no. 18, pp. 2780-2789, 2017.

[93] W. C. Skarnes, B. Rosen, A. P. West et al., "A conditional knockout resource for the genome-wide study of mouse gene function," Nature, vol. 474, no. 7351, pp. 337-342, 2011.

[94] Y. Huang, S. J. Pettitt, G. Guo et al., "Isolation of homozygous mutant mouse embryonic stem cells using a dual selection system," Nucleic Acids Research, vol. 40, no. 3, p. e21, 2012.

[95] G. Luo, I. M. Santoro, L. D. McDaniel et al., "Cancer predisposition caused by elevated mitotic recombination in bloom mice," Nature Genetics, vol. 26, no. 4, pp. 424-429, 2000. 
[96] G. Guo, W. Wang, and A. Bradley, "Mismatch repair genes identified using genetic screens in Blm-deficient embryonic stem cells," Nature, vol. 429, no. 6994, pp. 891-895, 2004.

[97] K. Yusa, K. Horie, G. Kondoh et al., "Genome-wide phenotype analysis in ES cells by regulated disruption of Bloom's syndrome gene," Nature, vol. 429, no. 6994, pp. 896-899, 2004.

[98] M. Yi, N. Hong, and Y. Hong, "Generation of medaka fish haploid embryonic stem cells," Science, vol. 326, no. 5951, pp. 430-433, 2009.

[99] U. Elling, J. Taubenschmid, G. Wirnsberger et al., "Forward and reverse genetics through derivation of haploid mouse embryonic stem cells," Cell Stem Cell, vol. 9, no. 6, pp. 563$574,2011$.

[100] M. Leeb and A. Wutz, "Derivation of haploid embryonic stem cells from mouse embryos," Nature, vol. 479, no. 7371, pp. 131-134, 2011.

[101] W. Li, L. Shuai, H. Wan et al., "Androgenetic haploid embryonic stem cells produce live transgenic mice," Nature, vol. 490, no. 7420, pp. 407-411, 2012.

[102] H. Yang, L. Shi, B. A. Wang et al., "Generation of genetically modified mice by oocyte injection of androgenetic haploid embryonic stem cells," Cell, vol. 149, no. 3, pp. 605-617, 2012.

[103] W. Li, X. Li, T. Li et al., "Genetic modification and screening in rat using haploid embryonic stem cells," Cell Stem Cell, vol. 14, no. 3, pp. 404-414, 2014.

[104] H. Yang, Z. Liu, Y. Ma et al., "Generation of haploid embryonic stem cells from Macaca fascicularis monkey parthenotes," Cell Research, vol. 23, no. 10, pp. 1187-1200, 2013.

[105] I. Sagi, G. Chia, T. Golan-Lev et al., "Derivation and differentiation of haploid human embryonic stem cells," Nature, vol. 532, no. 7597, pp. 107-111, 2016.

[106] C. Zhong, M. Zhang, Q. Yin et al., "Generation of human haploid embryonic stem cells from parthenogenetic embryos obtained by microsurgical removal of male pronucleus," Cell Research, vol. 26, no. 6, pp. 743-746, 2016.

[107] X. M. Zhang, K. Wu, Y. Zheng et al., "In vitro expansion of human sperm through nuclear transfer," Cell Research, vol. 30, no. 4, pp. 356-359, 2020.

[108] M. Leeb, S. Dietmann, M. Paramor, H. Niwa, and A. Smith, "Genetic exploration of the exit from self-renewal using haploid embryonic stem cells," Cell Stem Cell, vol. 14, no. 3, pp. 385-393, 2014.

[109] C. Zhong, Q. Yin, Z. Xie et al., "CRISPR-Cas9-mediated genetic screening in mice with haploid embryonic stem cells carrying a guide RNA library," Cell Stem Cell, vol. 17, no. 2, pp. 221-232, 2015.

[110] A. Monfort, G. Di Minin, A. Postlmayr et al., "Identification of Spen as a Crucial Factor for Xist Function through Forward Genetic Screening in Haploid Embryonic Stem Cells," Cell Reports, vol. 12, no. 4, pp. 554-561, 2015.

[111] J. V. Forment, M. Herzog, J. Coates et al., "Genome-wide genetic screening with chemically mutagenized haploid embryonic stem cells," Nature Chemical Biology, vol. 13, no. 1, pp. 12-14, 2017.

[112] U. Elling, R. A. Wimmer, A. Leibbrandt et al., "A reversible haploid mouse embryonic stem cell biobank resource for functional genomics," Nature, vol. 550, no. 7674, pp. 114$118,2017$.

[113] S. J. Pettitt, D. B. Krastev, H. N. Pemberton et al., "Genomewide barcoded transposon screen for cancer drug sensitivity in haploid mouse embryonic stem cells," Scientific Data, vol. 4, no. 1, article 170020, 2017.

[114] Q. Li, Y. Li, S. Yang et al., "CRISPR-Cas9-mediated baseediting screening in mice identifies DND1 amino acids that are critical for primordial germ cell development," Nature Cell Biology, vol. 20, no. 11, pp. 1315-1325, 2018.

[115] A. Yilmaz, M. Peretz, A. Aharony, I. Sagi, and N. Benvenisty, "Defining essential genes for human pluripotent stem cells by CRISPR-Cas9 screening in haploid cells," Nature Cell Biology, vol. 20, no. 5, pp. 610-619, 2018.

[116] M. Bai, Y. Han, Y. Wu et al., "Targeted genetic screening in mice through haploid embryonic stem cells identifies critical genes in bone development," PLoS Biology, vol. 17, no. 7, article e3000350, 2019.

[117] T. Cui, Z. Li, Q. Zhou, and W. Li, "Current advances in haploid stem cells," Protein \& Cell, vol. 11, no. 1, pp. 23-33, 2020.

[118] K. Peng, X. Li, C. Wu et al., "Derivation of Haploid Trophoblast Stem Cells via Conversion In Vitro," iScience, vol. 11, pp. 508-518, 2019.

[119] G. Guo, J. Yang, J. Nichols et al., "Klf4 reverts developmentally programmed restriction of ground state pluripotency," Development, vol. 136, no. 7, pp. 1063-1069, 2009.

[120] A. Gillich, S. Bao, N. Grabole et al., "Epiblast stem cell-based system reveals reprogramming synergy of germline factors," Cell Stem Cell, vol. 10, no. 4, pp. 425-439, 2012.

[121] S. Bao, F. Tang, X. Li et al., "Epigenetic reversion of postimplantation epiblast to pluripotent embryonic stem cells," Nature, vol. 461, no. 7268, pp. 1292-1295, 2009.

[122] Q. Gao, W. Zhang, Y. Zhao et al., "High-throughput screening in postimplantation haploid epiblast stem cells reveals Hs3st3b1 as a modulator for reprogramming," Stem Cells Translational Medicine, vol. 10, no. 5, pp. 743-755, 2021.

[123] G. Zhang, X. Li, Y. Sun, X. Wang, G. Liu, and Y. Huang, "A Genetic Screen Identifies Etl4-Deficiency Capable of Stabilizing the Haploidy in Embryonic Stem Cells," Stem Cell Reports, vol. 16, no. 1, pp. 29-38, 2021.

[124] S. J. Pettitt, F. L. Rehman, I. Bajrami et al., "A genetic screen using the PiggyBac transposon in haploid cells identifies Parp1 as a mediator of olaparib toxicity," PLoS One, vol. 8, no. 4, article e61520, 2013.

[125] J. E. Carette, C. P. Guimaraes, I. Wuethrich et al., "Global gene disruption in human cells to assign genes to phenotypes by deep sequencing," Nature Biotechnology, vol. 29, no. 6, pp. 542-546, 2011.

[126] J. Mao, K. Xu, J. Han, G. Feng, Y. Zhang, and W. Li, "Rapid construction of a whole-genome mutant library by combining haploid stem cells and inducible self-inactivating PiggyBac transposon," Protein \& Cell, vol. 11, no. 6, pp. 452-457, 2020.

[127] U. Weissbein, M. Peretz, O. Plotnik et al., "Genome-wide screen for culture adaptation and tumorigenicity-related genes in human pluripotent stem cells," iScience, vol. 11, pp. 398-408, 2019.

[128] A. J. Dupuy, K. Akagi, D. A. Largaespada, N. G. Copeland, and N. A. Jenkins, "Mammalian mutagenesis using a highly mobile somatic Sleeping Beauty transposon system," Nature, vol. 436, no. 7048, pp. 221-226, 2005.

[129] A. Wutz, "Haploid mouse embryonic stem cells: rapid genetic screening and germline transmission," Annual Review of Cell and Developmental Biology, vol. 30, no. 1, pp. 705-722, 2014. 
[130] W. Liu, C. Deng, C. Godoy-Parejo, Y. Zhang, and G. Chen, "Developments in cell culture systems for human pluripotent stem cells," World Journal of Stem Cells, vol. 11, no. 11, pp. 968-981, 2019.

[131] Y. Yang, B. Liu, J. Xu et al., "Derivation of pluripotent stem cells with in vivo embryonic and extraembryonic potency," Cell, vol. 169, no. 2, pp. 243-257.e25, 2017.

[132] X. Gao, M. Nowak-Imialek, X. Chen et al., "Establishment of porcine and human expanded potential stem cells," Nature Cell Biology, vol. 21, no. 6, pp. 687-699, 2019.

[133] J. Yang, D. J. Ryan, W. Wang et al., "Establishment of mouse expanded potential stem cells," Nature, vol. 550, no. 7676, pp. 393-397, 2017.

[134] J. Yang, D. J. Ryan, G. Lan, X. Zou, and P. Liu, "In vitro establishment of expanded-potential stem cells from mouse pre-implantation embryos or embryonic stem cells," Nature Protocols, vol. 14, no. 2, pp. 350-378, 2019.

[135] L. Yang, Y. Han, B. E. Nilsson-Payant et al., "A human pluripotent stem cell-based platform to study SARS-CoV-2 tropism and model virus infection in human cells and organoids," Cell Stem Cell, vol. 27, no. 1, pp. 125-136.e7, 2020.

[136] F. Wu, Y. Chen, K. You et al., "Generation of WAe001-A-58 human embryonic stem cell line with inducible expression of the SARS-CoV-2 nucleocapsid protein," Stem Cell Research, vol. 53, article 102197, 2021.

[137] K. Woltjen, I. P. Michael, P. Mohseni et al., "piggyBac transposition reprograms fibroblasts to induced pluripotent stem cells," Nature, vol. 458, no. 7239, pp. 766-770, 2009.

[138] K. Yusa, R. Rad, J. Takeda, and A. Bradley, "Generation of transgene-free induced pluripotent mouse stem cells by the _piggyBac_transposon," Nature Methods, vol. 6, no. 5, pp. 363-369, 2009.

[139] H. S. Kim, J. M. Bernitz, D. F. Lee, and I. R. Lemischka, "Genomic editing tools to model human diseases with isogenic pluripotent stem cells," Stem Cells and Development, vol. 23, no. 22, pp. 2673-2686, 2014.

[140] G. Wang, L. Yang, D. Grishin et al., "Efficient, footprint-free human iPSC genome editing by consolidation of Cas9/CRISPR and piggyBac technologies," Nature Protocols, vol. 12, no. 1, pp. 88-103, 2017.

[141] X. Xu, Y. Tay, B. Sim et al., "Reversal of phenotypic abnormalities by CRISPR/Cas9-mediated gene correction in Huntington disease patient-derived induced pluripotent stem cells," Stem Cell Reports, vol. 8, no. 3, pp. 619-633, 2017.

[142] T. I. Cornu, C. Mussolino, and T. Cathomen, "Refining strategies to translate genome editing to the clinic," Nature Medicine, vol. 23, no. 4, pp. 415-423, 2017.

[143] J. Shendure, S. Balasubramanian, G. M. Church et al., "DNA sequencing at 40: past, present and future," Nature, vol. 550, no. 7676, pp. 345-353, 2017.

[144] E. Zeggini, A. L. Gloyn, A. C. Barton, and L. V. Wain, "Translational genomics and precision medicine: moving from the lab to the clinic," Science, vol. 365, no. 6460, pp. 1409-1413, 2019.

[145] L. Mátés, M. K. Chuah, E. Belay et al., "Molecular evolution of a novel hyperactive Sleeping Beauty transposase enables robust stable gene transfer in vertebrates," Nature Genetics, vol. 41, no. 6, pp. 753-761, 2009.
[146] I. Grabundzija, M. Irgang, L. Mátés et al., "Comparative analysis of transposable element vector systems in human cells," Molecular Therapy, vol. 18, no. 6, pp. 1200-1209, 2010.

[147] J. E. Doherty, L. E. Huye, K. Yusa, L. Zhou, N. L. Craig, and M. H. Wilson, "Hyperactive piggyBac gene transfer in human cells and in vivo," Human Gene Therapy, vol. 23, no. 3, pp. 311-320, 2012.

[148] S. Wen, H. Zhang, Y. Li et al., "Characterization of constitutive promoters for piggyBac transposon-mediated stable transgene expression in mesenchymal stem cells (MSCs)," PLoS One, vol. 9, no. 4, article e94397, 2014.

[149] Y. Shu, C. Yang, X. Ji et al., "Reversibly immortalized human umbilical cord-derived mesenchymal stem cells (UC-MSCs) are responsive to BMP9-induced osteogenic and adipogenic differentiation," Journal of Cellular Biochemistry, vol. 119, no. 11, pp. 8872-8886, 2018.

[150] V. Bahrambeigi, N. Ahmadi, S. Moisyadi, J. Urschitz, R. Salehi, and S. Haghjooy Javanmard, "PhiC31/PiggyBac modified stromal stem cells: effect of interferon $\gamma$ and/or tumor necrosis factor (TNF)-related apoptosis-inducing ligand (TRAIL) on murine melanoma," Molecular Cancer, vol. 13, no. 1, p. 255, 2014.

[151] M. Loperfido, S. Jarmin, S. Dastidar et al., "piggyBac transposons expressing full-length human dystrophin enable genetic correction of dystrophic mesoangioblasts," Nucleic Acids Research, vol. 44, no. 2, pp. 744-760, 2016.

[152] S. Saha, L. E. Woodard, E. M. Charron, R. C. Welch, C. M. Rooney, and M. H. Wilson, "Evaluating the potential for undesired genomic effects of the piggyBac transposon system in human cells," Nucleic Acids Research, vol. 43, no. 3, pp. 1770-1782, 2015.

[153] S. K. Saridey, L. Liu, J. E. Doherty et al., "PiggyBac Transposon-based Inducible Gene Expression In Vivo After Somatic Cell Gene Transfer," Molecular Therapy, vol. 17, no. 12, pp. 2115-2120, 2009.

[154] S. R. Yant, L. Meuse, W. Chiu, Z. Ivics, Z. Izsvak, and M. A. Kay, "Somatic integration and long-term transgene expression in normal and haemophilic mice using a DNA transposon system," Nature Genetics, vol. 25, no. 1, pp. 35-41, 2000.

[155] T. Cui, L. Jiang, T. Li et al., "Derivation of mouse haploid trophoblast stem cells," Cell Reports, vol. 26, no. 2, pp. 407414.e5, 2019.

[156] S. Gayle, Y. Pan, S. Landrette, and T. Xu, "piggyBac Insertional Mutagenesis Screen Identifies a Role for Nuclear RHOA in Human ES Cell Differentiation," Stem Cell Reports, vol. 4, no. 5, pp. 926-938, 2015. 